\title{
Analysis of Wavelet Transform for Image Denoising with MSE
}

\author{
Komal Vijay \\ M.Tech Student \\ IET Alwar, (Raj)
}

\author{
Pratap Singh Patwal \\ Associate Professor, \\ CSE, IET Alwar (Raj)
}

\author{
Kapil Sharma \\ Assistant Professor, \\ CSE, IET Alwar (Raj)
}

\begin{abstract}
A Great challenge is to obtain an efficient method for removing noise from the images. Noise can contaminate the image at time of capturing or transmission. The method of removing noise from image depends on the type of noise present in image. In this, different types of noise and analysis of noise removal techniques is presented. Here, result of applying various noise types to image and also results of applying various filters to those noisy images have been presented. Quantitative measure of comparison is provided by several quality parameters on the image. The parameters used are: Mean Square Error (MSE), Peak signal to noise ratio (PSNR), and Universal Image Quality Index. Whenever an image is reconstructed, the quality of reconstructed image is calculated in terms of various quality parameters. MSE is considered as one of the most reliable and widely used quality parameter however, we are using a new universal image quality index $\mathrm{Q}$, which proves to be better than MSE. An improvisation of the same has also been proposed in this report. The noisy image is reconstructed by using wavelets on filtered image. The image is filtered using wiener filter i.e. frequency domain filtering followed by application of wavelets. The fact that the image reconstructed by this method is better than that reconstructed using other methods is proved to be true by examining the value of quality parameters MSE and PSNR. The value of MSE obtained by the above mentioned technique is found to be the smallest among all values of MSE obtained by other techniques i.e. the most favourable till now. Similarly the value of PSNR calculated by this technique is the highest obtained till now. Hence, we can say that the method adopted in this report to reconstruct an image from a noisy image is by far the best technique encountered till now.
\end{abstract}

\section{Keywords}

Image compression, wavelets, storage, etc.

\section{INTRODUCTION}

As the name suggests, Wavelets are small time limited waves having zero average value [3]. Different types of available wavelets are shown in Table. These wavelets are the basis function for wavelet analysis. Several families of wavelets that have proven to be especially useful are included in the wavelet toolbox [10]. The details of these wavelet Families have been shown below. ** Following wavelets in the last column of the table indicate a wavelet being a part of an infinite family of wavelets.

\begin{tabular}{|c|c|c|c|}
\hline $\begin{array}{l}\text { Sr. } \\
\text { No }\end{array}$ & $\begin{array}{l}\text { Mother } \\
\text { wavelet } \\
\text { family } \\
\text { names }\end{array}$ & Abbreviations & Wavelets \\
\hline 1 & Haar & Haar & \\
\hline 2 & Daubechies & $\mathrm{Db}$ & $\begin{array}{l}\text { db1 db2 db3 db4 db5 db6 } \\
\text { db7 db8 } \\
\text { db9 db10 db** }\end{array}$ \\
\hline 3 & Symlets & Sym & $\begin{array}{l}\text { sym2 sym3 sym4 sym5 } \\
\text { sym6 sym7 sym8 } \\
\text { sym** }\end{array}$ \\
\hline 4 & Coiflets & Coif & $\begin{array}{llll}\text { coif1 } & \text { coif2 } & \text { coif3 } & \text { coif4 } \\
\text { coif5 } & & & \end{array}$ \\
\hline 5 & BiorSplines & Bior & $\begin{array}{l}\text { bior } 1.1 \text { bior } 1.3 \text { bior } 1.5 \\
\text { bior } 2.2 \text { bior } 2.4 \text { bior } 2.6 \\
\text { bior } 2.8 \text { bior } 3.1 \text { bior } 3.3 \\
\text { bior } 3.5 \text { bior } 3.7 \text { bior } 3.9 \\
\text { bior } 4.4 \text { bior } 5.5 \text { bior6. } 8\end{array}$ \\
\hline 6 & ReverseBior & Rbio & $\begin{array}{l}\text { rbio1. } 1 \text { rbio1.3 rbio1.5 } \\
\text { rbio2. } 2 \text { rbio2. } 4 \text { rbio } 2.6 \\
\text { rbio2.8 } 6 \text { rbio3.1 rbio3.3 } \\
\text { rbio3.5 rbio3.7 rbio3.9 } \\
\text { rbio4. } 4 \text { rbio5.5 rbio6.8 }\end{array}$ \\
\hline 7 & Meyer & Meyr & \\
\hline 8 & DMeyer & Dmey & \\
\hline 9 & Gaussian & Gaus & $\begin{array}{l}\text { gaus } 1 \text { gaus } 2 \text { gaus } 3 \text { gaus } 4 \\
\text { gaus5gaus6 gaus } 7 \\
\text { gaus8 gaus** }\end{array}$ \\
\hline 10 & Mexican_hat & Mexh & \\
\hline 11 & Morlet & Morl & \\
\hline 12 & $\begin{array}{l}\text { Complex } \\
\text { Gaussian }\end{array}$ & Gaus & $\begin{array}{l}\text { cgau } 1 \text { cgau2cgau } 3 \text { cgau } 4 \\
\text { cgau } 5 \text { cgau** }\end{array}$ \\
\hline 13 & Shannon & Shan & $\begin{array}{l}\text { shan1-1.5 shan 1-1 shan1- } \\
0.5 \text { shan1- } \\
0.1 \text { shan2-3 shan** }\end{array}$ \\
\hline 14 & $\begin{array}{l}\text { Frequency } \\
\text { B-Spline }\end{array}$ & Fbsp & $\begin{array}{l}\text { fbsp1-1-1.5 fbsp1-1-1 } \\
\text { fbsp1-1-0.5 fbsp2-1-1 } \\
\text { fbsp2-1-0.5 fbsp2-1-0.1 } \\
\text { fbsp** }\end{array}$ \\
\hline 15 & $\begin{array}{l}\text { Complex } \\
\text { Morlet }\end{array}$ & Cmor & $\begin{array}{l}\text { cmor } 1-1.5 \text { cmor } 1-1 \\
\text { cmor } 1-0.5 \text { cmor } 1-0.1 \\
\text { cmor** }\end{array}$ \\
\hline
\end{tabular}

The Discrete Wavelet Transform, which is based on sub-band coding, is found to yield a fast computation of Wavelet Transform [52][59]. It is easy to implement and reduces the computation time and resources required. The discrete wavelet transform uses filter banks for the construction of the multiresolution time-frequency plane. The Discrete Wavelet Transform analyzes the signal at different frequency bands with different resolutions by decomposing the signal into an approximation and detail information. 


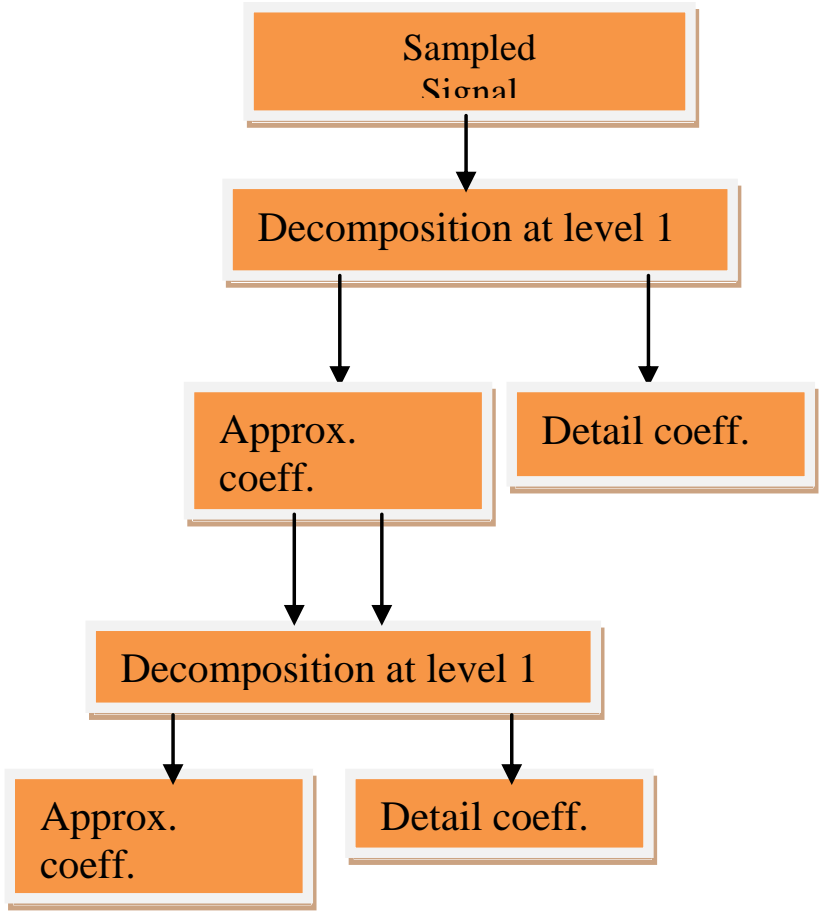

Fig 1: Flow of Wavelet - Multi-level Decomposition

The decomposition of the signal into different frequency bands obtained by successive high pass $\mathrm{g}[\mathrm{n}]$ and low pass $\mathrm{h}[\mathrm{n}]$ filtering of the time domain signal. The combination of high pass $\mathrm{g}[\mathrm{n}]$ and low pass filter $\mathrm{h}[\mathrm{n}]$ comprise a pair of analyzing filters The output of each filter contains half the frequency content, but an equal amount of samples as the input signal. The two outputs together contain the same frequency content as the input signal; however the amount of data is doubled. Therefore down sampling by a factor two, denoted by 2, is applied to the outputs of the filters in the analysis bank. Reconstruction of the original signal is possible using the synthesis filter bank. In the synthesis bank the signals are up sampled and passed through the filters $g[n]$ and $h[n]$. The filters in the synthesis bank are based on the filters in the analysis bank.

\section{LITERATURE SURVEY}

Archana., et al. (2014) [1] proposed a theory based on image restoration methods. It explains digital image processing and describes 3 types of noise which are Gaussian, salt and pepper and speckle noise. Proliferation of Digital Images across the internet has given rise to more systematic and effective image restoration methods. Process of image restoration involves procuring noise free original image from a corrupted noisy image. This process of image restoration is crucial in many areas such as satellite imaging, astronomical image \& medical imaging where degraded images need to be repaired. This paper provides a review of various Denoising Techniques in Image Restoration. The Denoising Techniques uses Linear and Non Linear Filters. It explains mean, median and adaptive filter in brief. The technique used for image restoration is Nearest Neighbour method along with Contrast and Saturation technique.

Attlas N., et al. (2014) [2] proposed a theory based on various techniques for reduction of speckle noise in ultrasound images. De-noising plays a very important role in the field of the biomedical image pre-processing. It is often done before the image data is to be analyzed. This paper presents a review of various techniques for reduction of speckle noise in ultrasound images. Speckle Noise is one of the most prominent noises seen in the ultrasound images and corrupts the visual quality of the image for further processing being multiplicative in nature. This paper demonstrates wavelet based techniques for improving visual image quality in ultrasound images and Denoising. With the help of variable window technique and region based processing; discrete wavelet transform technique provided better noise rejection in ultrasound images by removing the speckle noise.

Anutam., et al. (2014) [3] proposed a theory based on comparison of various wavelets at different decomposition levels. PSNR, MAE and MSE are the measures used for comparing image quality. Comparison of filters with wavelet based methods has also been carried out to De-noise image. Image Denoising is an important part of diverse image processing and computer vision problems. The important property of a good image de-noising model is that it should completely remove noise as far as possible as well as preserve edges. One of the most powerful and perspective approaches in this area is image de-noising using discrete wavelet transform (DWT). In this paper, comparison of various Wavelets at different decomposition levels has been done. As number of levels increased, Peak Signal to Noise Ratio (PSNR) of image gets decreased whereas Mean Absolute Error (MAE) and Mean Square Error (MSE) get increased. A comparison of filters and various wavelet based methods has also been carried out to de-noise the image. The simulation results reveal that wavelet based Bayes shrinkage method outperforms other methods.

Mandot M., et al. (2014) [4] proposed a theory based on preprocessing step of digital imaging, noise present in digital image and how filtering technique improves the quality of image and reduces noises in synthesis medical images. Now a day in regular emerging field of technology use of digital imaging grows. Digital image processing refers to processing of digital images by the digital computer to improve the quality of image and enhancing the image and their edges. DIP is vast area of work. This digital image processing is used in many fields like in photography, high security number plate recognition system and in medical field also. This paper mainly focuses on pre- processing step of digital imaging, noise present in digital image and how filtering technique improves the quality of image and reduces the noise in synthesis medical images. In this paper we take ultrasound medical images for pre-processing on digital image processing. So the input is ultrasound image for preprocessing. This paper describes type of noise and a new filtering technique for removing blurriness. Result is based on isualization and histogram of image.

Daway H., (2014) [5] proposed a theory based on a Mode Filter (MF) to reduce salt and pepper noise. The metrics for comparison used are PSNR, MSE, and IEF. A mode filter (MF) is proposed to remove high density salt \& pepper noise from images. First stage in this algorithm the pixels with noise are detected and in the second stage each noisy pixel has been replaced by the mode value, after reduced range and estimate all noise value (0's and 255's) from the kernel. The proposed algorithm MF shows significantly better image quality than a simple median filter (SMF), adapted mean filter (AMF), Decision Based Algorithm (DBA) and Decision Based Unsymmetric Trimmed Median Filter (MDBUTMF). The proposed algorithm is examined with different gray image and it appears better Peak Signal-to-Noise Ratio (PSNR) and Image Enhancement Factor (IEF). 


\section{IMAGE DE-NOISE ALGORITHMS}

The process adopted in filtering noisy image has been described with the help of block diagram and in detailed steps given below

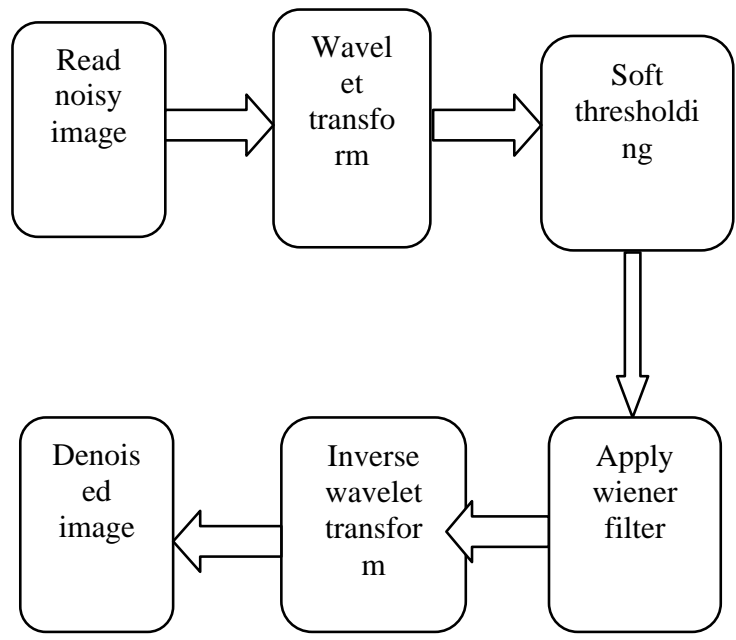

Fig 2: Process of proposed algorithm

Step 1:- Read the noisy image as input.

Read image from the hard disk with the help of inbuilt function. e.g.

$\mathrm{I}=$ imread('I.png');

Step 2:- Decide name of wavelet family.

Use any one wavelet from the various wavelets family (db145 and others).

Step 3:- Decide density of noise used by wiener filter, which should be $>=0.01$.

Use Numeric Value as a parameter to add noise density in the image.

Step 4:- Use odd size mask for low frequency sub-band.

Always use odd mask size like $3 \times 3,5 \times 5,7 \times 7 \ldots$ etc for low frequency sub-band because odd size of mask has center value.

Step 5:- Use odd size mask for high frequency sub-band.

Always use odd mask size like $3 \times 3,5 \times 5,7 \times 7$..etc for high frequency sub-band because odd size of mask has center value.

Step 6:- Apply first level dwt (Single-level discrete 2-D wavelet transform)

The dwt 2 command performs a single-level two-dimensional wavelet decomposition with respect to either a particular wavelet ('wname') or particular.wavelet decomposition filters (Lo_D and Hi_D) you specify.

$[\mathrm{cA}, \mathrm{cH}, \mathrm{cV}, \mathrm{cD}]=\operatorname{dwt} 2\left(\mathrm{X},{ }^{\prime}\right.$ wname') computes the approximation coefficients matrix cA and details coefficients matrices $\mathrm{cH}, \mathrm{cV}$, and $\mathrm{cD}$ (horizontal, vertical, and diagonal, respectively), obtained by wavelet decomposition of the input matrix $X$. The 'wname' string contains the wavelet name.
Step 7:- Apply second level dwt on output obtained in previous step

$[\mathrm{AA}, \mathrm{AB}, \mathrm{AC}, \mathrm{AD}]=\mathrm{dwt} 2(\mathrm{cA}$, wname $)$;

Step 8:- Apply soft thresholding i.e. remove noise from high frequency domain in dwt.

Apply first level soft-Thresolding in each block $\mathrm{cH}, \mathrm{cV}$ and $\mathrm{cD}$ respectively than again apply second level soft-Thresolding in each block $\mathrm{AB}, \mathrm{AC}$ and $\mathrm{AD}$ respectively.

\section{Step 9:- Apply wiener filter.}

2-D adaptive noise-removal filtering is a lowpass filter, a grayscale image that has been degraded by constant power additive noise. wiener 2 uses a pixel-wise adaptive Wiener method based on statistics estimated from a local neighbor hood of each pixel.

Step 10:- Apply inverse dwt for second level.

The idwt 2 command performs a single-level two-dimensional wavelet reconstruction with respect to either a particular wavelet ('wname', see wfilters for more information) or particular wavelet reconstruction filters (Lo_Rand Hi_R) that you specify.

\section{Step 11:- Apply inverse dwt for first level.}

Same process will be implemented for first level as mentioned in step 10.

\section{Step 12:- Save denoised image.}

Write image to graphics file. imwrite(A,filename,fmt) writes the image $\mathrm{A}$ to the file specified by filename in the format specified by fmt.

\section{IMAGE DE-NOISE TOOL}

Finally, the reconstructed (denoised) image is compared with the original image by means of quality parameters MSE and PSNR. These values help us estimate the extent of reconstruction.

When we click on button filter_Apply execution of proposed algorithms which is define in section 3 is start. In the process three different images have already stored on the hard disk first input image, second noisy image and third filtered image. For second phase of the tool click on quality button, browse window will be open and ask to import original image and filtered image once you import the images it will give the values of MSE and PSNR, to check the accuracy or for comparisons we need the value of MSE and PSNR for the input image and noise image which should be degraded.

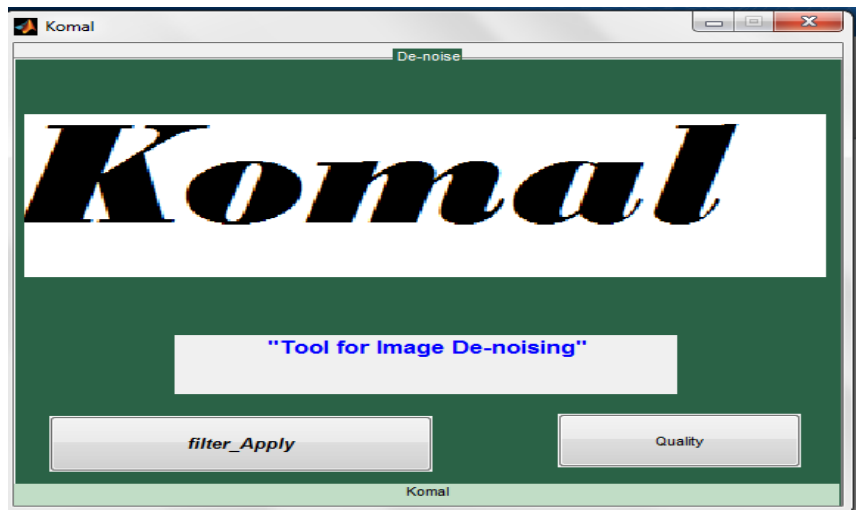

Fig 3: GUI 


\section{RESULT}

Results are formulated and presented in form of Tables. First of all, the values of MSE and PSNR are calculated for order static filters, which come out to be unsatisfactory. Next, a new universal image quality index is used as a quality parameter and also histogram equalization is performed on images in order to improve value of new quality index. Later in this chapter, frequency domain filtering followed by application of wavelets is done and values of MSE and PSNR are recorded for the same. The values stored make it clear that which technique is best in process of noise removal and image reconstruction.

In the below there are two image first input image and second noisy image with gaussian noise. Our objective is to remove the noise from the second image and compare with first image that how much we are close to ideal image after the filtering.
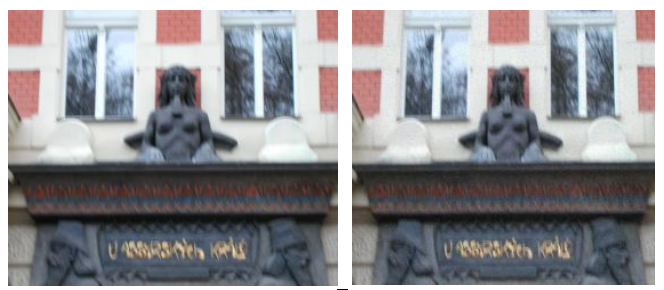

Fig 4: Input Image Fig 5: Gaussian Noise

Table 1: MseAndPsnr Values For Gaussian Noise

\begin{tabular}{|c|c|c|c|}
\hline $\begin{array}{l}\text { Quality } \\
\text { parameter }\end{array}$ & $\begin{array}{l}\text { R } \\
\text { component }\end{array}$ & $\begin{array}{l}\text { G } \\
\text { component }\end{array}$ & $\begin{array}{l}\text { B } \\
\text { component }\end{array}$ \\
\hline MSE & 237.0562 & 231.3223 & 228.8254 \\
\hline PSNR & 24.3823 & 24.4886 & 24.5358 \\
\hline
\end{tabular}

The values of parameters obtained above without proposed filter or wavelets and are un-favourable.

Table 2: Haar Wavelet Values For Gaussian Noise

\begin{tabular}{|c|c|c|c|}
\hline $\begin{array}{l}\text { Quality } \\
\text { parameter }\end{array}$ & $\begin{array}{l}\mathbf{R} \\
\text { component }\end{array}$ & $\begin{array}{l}\text { G } \\
\text { component }\end{array}$ & $\begin{array}{l}\text { B } \\
\text { component }\end{array}$ \\
\hline MSE & 140.5669 & 125.1484 & 122.8254 \\
\hline PSNR & 26.6520 & 27.1565 & 27.2570 \\
\hline
\end{tabular}

The values of parameters get improved than original values and are obtained by applied wavelets 'haar' with proposed filter.

Table 3:Db Wavelet Family Values For Gaussian Noise

\begin{tabular}{|c|c|c|c|c|}
\hline $\begin{array}{l}\text { Type } \\
\text { of } \\
\text { wavele } \\
t\end{array}$ & $\begin{array}{l}\text { Quality } \\
\text { paramete } \\
\text { r }\end{array}$ & $\begin{array}{l}\text { R } \\
\text { componen } \\
t\end{array}$ & $\begin{array}{l}\text { G } \\
\text { componen } \\
t\end{array}$ & $\begin{array}{l}\text { B } \\
\text { componen } \\
\text { t }\end{array}$ \\
\hline \multirow[t]{2}{*}{ db1 } & MSE & 140.5669 & 125.1484 & $\begin{array}{l}122.28 \\
78\end{array}$ \\
\hline & PSNR & 26.6520 & 27.1565 & $\begin{array}{l}27.257 \\
0\end{array}$ \\
\hline \multirow[t]{2}{*}{ db2 } & MSE & 210.5146 & 190.4105 & $\begin{array}{l}185.09 \\
31\end{array}$ \\
\hline & PSNR & 24.8980 & 25.3339 & $\begin{array}{l}25.456 \\
9\end{array}$ \\
\hline db3 & MSE & 83.9162 & 75.1645 & 74.677 \\
\hline
\end{tabular}

\begin{tabular}{|c|c|c|c|c|}
\hline & & & & 8 \\
\hline & PSNR & 28.8923 & 29.3707 & $\begin{array}{l}29.398 \\
9\end{array}$ \\
\hline \multirow[t]{2}{*}{ db4 } & MSE & 121.7556 & 107.3875 & $\begin{array}{l}105.27 \\
82\end{array}$ \\
\hline & PSNR & 27.2759 & 27.8213 & $\begin{array}{l}27.907 \\
4\end{array}$ \\
\hline \multirow[t]{2}{*}{ db5 } & MSE & 188.0450 & 168.8309 & $\begin{array}{l}164.14 \\
83\end{array}$ \\
\hline & PSNR & 25.3882 & 25.8563 & $\begin{array}{l}25.978 \\
4\end{array}$ \\
\hline \multirow[t]{2}{*}{ db6 } & MSE & 259.9101 & 237.4373 & $\begin{array}{l}230.62 \\
27\end{array}$ \\
\hline & PSNR & 23.9826 & 24.3753 & $\begin{array}{l}24.501 \\
8\end{array}$ \\
\hline \multirow[t]{2}{*}{ db7 } & MSE & 102.2316 & 90.1505 & $\begin{array}{l}88.876 \\
5\end{array}$ \\
\hline & PSNR & 28.0350 & 28.5811 & $\begin{array}{l}28.642 \\
9\end{array}$ \\
\hline \multirow[t]{2}{*}{ db8 } & MSE & 165.2622 & 146.3788 & $\begin{array}{l}143.53 \\
95\end{array}$ \\
\hline & PSNR & 25.9491 & 26.4465 & $\begin{array}{l}26.561 \\
1\end{array}$ \\
\hline \multirow[t]{2}{*}{ db9 } & MSE & 235.6039 & 214.1133 & $\begin{array}{l}207.97 \\
01\end{array}$ \\
\hline & PSNR & 24.4090 & 24.8244 & $\begin{array}{l}24.950 \\
8\end{array}$ \\
\hline \multirow[t]{2}{*}{ db10 } & MSE & 122.0873 & 107.6079 & $\begin{array}{l}105.51 \\
34\end{array}$ \\
\hline & PSNR & 27.2641 & 27.8124 & $\begin{array}{l}27.897 \\
7\end{array}$ \\
\hline \multirow[t]{2}{*}{ db11 } & MSE & 143.2268 & 126.8956 & $\begin{array}{l}123.91 \\
08\end{array}$ \\
\hline & PSNR & 26.5706 & 27.0963 & $\begin{array}{l}27.199 \\
7\end{array}$ \\
\hline \multirow[t]{2}{*}{ db12 } & MSE & 211.6468 & 191.2495 & $\begin{array}{l}185.81 \\
92\end{array}$ \\
\hline & PSNR & 24.8747 & 25.3148 & $\begin{array}{l}25.439 \\
9\end{array}$ \\
\hline \multirow[t]{2}{*}{ db13 } & MSE & 84.1956 & 75.3015 & $\begin{array}{l}74.794 \\
2\end{array}$ \\
\hline & PSNR & 28.8779 & 29.3628 & $\begin{array}{l}29.392 \\
1\end{array}$ \\
\hline \multirow[t]{2}{*}{ db14 } & MSE & 122.1987 & 107.7193 & $\begin{array}{l}105.55 \\
48\end{array}$ \\
\hline & PSNR & 27.2601 & 27.8079 & $\begin{array}{l}27.896 \\
0\end{array}$ \\
\hline \multirow[t]{2}{*}{ db15 } & MSE & 188.1893 & 168.9817 & $\begin{array}{l}164.32 \\
36\end{array}$ \\
\hline & PSNR & 25.3849 & 25.8524 & $\begin{array}{l}25.973 \\
8\end{array}$ \\
\hline \multirow[t]{2}{*}{ db16 } & MSE & 260.1243 & 237.6087 & $\begin{array}{l}230.79 \\
20\end{array}$ \\
\hline & PSNR & 23.9790 & 24.3722 & $\begin{array}{l}24.498 \\
6\end{array}$ \\
\hline db17 & MSE & 102.4274 & 90.3013 & $\begin{array}{l}88.994 \\
3 \\
\end{array}$ \\
\hline
\end{tabular}




\begin{tabular}{|lllll|}
\hline & PSNR & 28.0266 & 28.5739 & 28.637 \\
& & & & 2 \\
\hline db18 & MSE & 165.3729 & 147.5488 & 143.71 \\
& & & & 38 \\
& & & & 26.555 \\
& & 25.9462 & 26.4414 & 8 \\
\hline db20 & MSE & 122.3034 & 107.7865 & 105.63 \\
& & & & 01 \\
\cline { 2 - 5 } & PSNR & 27.2564 & 27.8052 & 27.892 \\
& & & & 9 \\
\hline db23 & MSE & 84.3800 & 75.4640 & 74.912 \\
& & & & 1 \\
\cline { 2 - 5 } & PSNR & 28.8684 & 29.3534 & 29.385 \\
& & & & 3 \\
\hline db25 & MSE & 188.3420 & 169.1185 & 164.48 \\
& & & & 09 \\
\cline { 2 - 5 } & PSNR & 25.3813 & 25.8489 & 25.969 \\
& & & & 6 \\
\hline db33 & MSE & 84.4533 & 75.5588 & 75.000 \\
& & & & 0 \\
\cline { 2 - 5 } & PSNR & 28.8646 & 29.3480 & 29.380 \\
& & & & 2 \\
\hline db43 & MSE & 84.4647 & 75.6271 & 75.090 \\
& & & & 6 \\
\cline { 2 - 5 } & PSNR & 28.8641 & 29.3440 & 29.374 \\
& & & 9 \\
\hline
\end{tabular}

$\mathrm{db} 3$ gives the best and most appropriate values for both the parameters; hence, $\mathrm{db} 3$ is the best member of this wavelet family for noise removal.

Table 4: Symlet Wavelet Family Values For Gaussian Noise

\begin{tabular}{|c|c|c|c|c|}
\hline $\begin{array}{l}\text { Type } \\
\text { of } \\
\text { wavele } \\
t\end{array}$ & $\begin{array}{l}\text { Quality } \\
\text { paramete } \\
\text { r }\end{array}$ & $\begin{array}{l}\text { R } \\
\text { componen } \\
\text { t }\end{array}$ & $\begin{array}{l}\text { G } \\
\text { componen } \\
\text { t }\end{array}$ & $\begin{array}{l}\text { B } \\
\text { componen } \\
t\end{array}$ \\
\hline \multirow[t]{2}{*}{ sym1 } & MSE & 140.5669 & 125.1484 & 122.2878 \\
\hline & PSNR & 26.6520 & 27.1565 & 27.2570 \\
\hline \multirow[t]{2}{*}{ sym2 } & MSE & 210.5146 & 190.4105 & 185.0931 \\
\hline & PSNR & 24.8980 & 25.3339 & 25.4569 \\
\hline \multirow[t]{2}{*}{ sym3 } & MSE & 83.9162 & 75.1645 & 74.6778 \\
\hline & PSNR & 28.8923 & 29.3707 & 29.3989 \\
\hline \multirow[t]{2}{*}{ sym4 } & MSE & 121.7164 & 107.3763 & 105.2900 \\
\hline & PSNR & 27.2773 & 27.8217 & 27.9069 \\
\hline \multirow[t]{2}{*}{ sym5 } & MSE & 188.0054 & 168.7083 & 164.0537 \\
\hline & PSNR & 25.3891 & 25.8594 & 25.9809 \\
\hline \multirow[t]{2}{*}{ sym6 } & MSE & 259.9063 & 237.4498 & 230.5483 \\
\hline & PSNR & 23.9826 & 24.3751 & 24.5032 \\
\hline \multirow[t]{2}{*}{ sym7 } & MSE & 102.1185 & 90.1621 & 88.9309 \\
\hline & PSNR & 28.0398 & 28.5806 & 28.6403 \\
\hline \multirow[t]{2}{*}{ sym8 } & MSE & 165.3166 & 147.3756 & 143.5555 \\
\hline & PSNR & 25.9476 & 26.4465 & 26.5606 \\
\hline \multirow[t]{2}{*}{ sym9 } & MSE & 235.6420 & 213.9995 & 207.8680 \\
\hline & PSNR & 24.4083 & 24.8267 & 24.9529 \\
\hline \multirow[t]{2}{*}{ sym10 } & MSE & 122.1133 & 107.7315 & 105.5795 \\
\hline & PSNR & 27.2632 & 27.8074 & 27.8950 \\
\hline
\end{tabular}

Sym3 gives the best and most appropriate values for both the parameters; hence, sym 3 is the best member of this wavelet family for noise removal.

Table 5:Dmey Wavelet Family Values For Gaussian Noise

\begin{tabular}{|llll|}
$\begin{array}{l}\text { Quality } \\
\text { parameter }\end{array}$ & $\begin{array}{l}\text { R } \\
\text { component }\end{array}$ & $\begin{array}{l}\text { G } \\
\text { component }\end{array}$ & $\begin{array}{l}\text { B component } \\
\text { comp }\end{array}$ \\
\hline MSE & 143.9384 & 127.4469 & 124.4412 \\
\hline PSNR & 26.5490 & 27.0775 & 27.1812 \\
\hline
\end{tabular}

This table gives the values of MSE and PSNR, when discrete approximation of Meyer wavelet is applied to images.

Table 6:Coiflets Wavelet Family Values For Gaussian Noise

\begin{tabular}{|lllll|}
$\begin{array}{l}\text { Type } \\
\text { of } \\
\text { wavele } \\
\mathbf{t}\end{array}$ & $\begin{array}{l}\text { Quality } \\
\text { paramete } \\
\mathbf{r}\end{array}$ & $\begin{array}{l}\mathbf{R} \\
\text { componen } \\
\mathbf{t}\end{array}$ & $\begin{array}{l}\mathbf{G} \\
\text { componen } \\
\mathbf{t}\end{array}$ & $\begin{array}{l}\text { B } \\
\text { componen } \\
\mathbf{t}\end{array}$ \\
\cline { 2 - 5 } & MSE & 84.0741 & 75.2217 & 74.6900 \\
\hline coif2 & PSNR & 28.8842 & 29.3674 & 29.3982 \\
\cline { 2 - 5 } & PSE & 259.7075 & 237.1542 & 230.3654 \\
\hline coif3 & MSE & 23.9860 & 24.3805 & 24.5066 \\
\cline { 2 - 5 } & PSNR & 24.4103 & 24.8280 & 24.9540 \\
\hline coif4 & MSE & 211.6738 & 191.1659 & 185.7459 \\
\cline { 2 - 5 } & PSNR & 24.8741 & 25.3167 & 25.4416 \\
\hline coif5 & MSE & 188.2761 & 168.9376 & 164.2740 \\
\cline { 2 - 5 } & PSNR & 25.3829 & 25.8535 & 25.9751 \\
\hline
\end{tabular}

coif1 gives the best and most appropriate values for both the parameters; hence, coif1 is the best member of this wavelet family for noise removal.

Table 7:Biorthogonal Wavelet Family Values For Gaussian Noise

\begin{tabular}{|lllll|}
$\begin{array}{l}\text { Type } \\
\text { of } \\
\text { wavele } \\
\mathbf{t}\end{array}$ & $\begin{array}{l}\text { Quality } \\
\text { paramete } \\
\mathbf{r}\end{array}$ & $\begin{array}{l}\mathbf{R} \\
\text { componen } \\
\mathbf{t}\end{array}$ & $\begin{array}{l}\mathrm{G} \\
\text { componen } \\
\mathbf{t}\end{array}$ & $\begin{array}{l}\text { B } \\
\text { componen } \\
\mathbf{t}\end{array}$ \\
\hline $\begin{array}{l}\text { bior1. } \\
\mathbf{1}\end{array}$ & MSE & 140.5669 & 125.1484 & 122.2878 \\
\cline { 2 - 5 } & PSNR & 26.6520 & 27.1565 & 27.2570 \\
\hline $\begin{array}{l}\text { bior1. } \\
\mathbf{3}\end{array}$ & MSE & 86.3121 & 77.2687 & 76.6436 \\
\cline { 2 - 5 } & PSNR & 28.7701 & 29.2508 & 29.2860 \\
\hline $\begin{array}{l}\text { bior1. } \\
\mathbf{5}\end{array}$ & MSE & 191.4449 & 171.7029 & 166.8391 \\
\cline { 2 - 5 } & PSNR & 25.3104 & 25.7830 & 25.9078 \\
\hline $\begin{array}{l}\text { bior2. } \\
\mathbf{2}\end{array}$ & MSE & 86.0207 & 77.1674 & 76.5723 \\
\cline { 2 - 5 } & PSNR & 28.7848 & 29.2565 & 29.2901 \\
\hline $\begin{array}{l}\text { bior2. } \\
\mathbf{4}\end{array}$ & MSE & 189.4208 & 170.2584 & 165.5348 \\
\cline { 2 - 5 } & PSNR & 25.3565 & 25.8197 & 25.9419 \\
\hline bior2. & MSE & 103.6923 & 91.4962 & 90.1308 \\
\cline { 2 - 5 } $\mathbf{6}$ & PSNR & 27.9733 & 28.5168 & 28.5821 \\
\hline & & & & \\
\hline
\end{tabular}




\begin{tabular}{|lllll|}
\hline bior2. & MSE & 237.5998 & 215.9908 & 209.6995 \\
\cline { 2 - 5 } $\mathbf{8}$ & PSNR & 24.3723 & 24.7865 & 24.9148 \\
\hline bior3. & MSE & 241.3863 & 220.7059 & 215.1474 \\
\cline { 2 - 5 } $\mathbf{1}$ & PSNR & 24.3037 & 24.6927 & 24.8034 \\
\hline $\begin{array}{l}\text { bior3. } \\
\mathbf{3}\end{array}$ & MSE & 126.7134 & 112.2248 & 110.0205 \\
\cline { 2 - 5 } & PSNR & 27.1026 & 27.6299 & 27.7161 \\
\hline $\begin{array}{l}\text { bior3. } \\
\mathbf{5}\end{array}$ & MSE & 263.3599 & 240.6773 & 233.7175 \\
\cline { 2 - 5 } & PSNR & 23.9253 & 24.3165 & 24.4439 \\
\hline $\begin{array}{l}\text { bior3. } \\
\mathbf{7}\end{array}$ & MSE & 168.1115 & 150.0168 & 146.0518 \\
\cline { 2 - 5 } & PSNR & 25.8748 & 26.3694 & 26.4857 \\
\hline $\begin{array}{l}\text { bior3. } \\
\mathbf{9}\end{array}$ & MSE & 124.6271 & 109.9055 & 107.6667 \\
\cline { 2 - 5 } & PSNR & 27.1747 & 27.7206 & 27.8100 \\
\hline $\begin{array}{l}\text { bior4. } \\
\mathbf{4}\end{array}$ & MSE & 187.6905 & 168.6667 & 164.0198 \\
\cline { 2 - 5 } & PSNR & 25.3964 & 25.8605 & 25.9818 \\
\hline bior5. & MSE & 257.7441 & 235.3675 & 228.6164 \\
& PSNR & 24.0189 & 24.4133 & 24.5397 \\
\hline $\begin{array}{l}\text { bior6. } \\
\mathbf{8}\end{array}$ & MSE & 235.8277 & 214.3490 & 208.1427 \\
\cline { 2 - 5 } & PSNR & 24.4049 & 24.8196 & 24.9472 \\
\hline
\end{tabular}

bior2.2 gives the best and most appropriate values for both the parameters; hence, bior2.2 is the best member of this wavelet family for noise removal.

\begin{tabular}{|c|c|c|c|c|}
\hline $\begin{array}{l}\text { Type } \\
\text { of } \\
\text { wavele } \\
t\end{array}$ & $\begin{array}{l}\text { Quality } \\
\text { paramete } \\
\text { r }\end{array}$ & $\begin{array}{l}\text { R } \\
\text { componen } \\
t\end{array}$ & $\begin{array}{l}\text { G } \\
\text { componen } \\
\mathrm{t}\end{array}$ & $\begin{array}{l}\text { B } \\
\text { componen } \\
\text { t }\end{array}$ \\
\hline \multirow{2}{*}{$\begin{array}{l}\text { rbio1. } \\
1\end{array}$} & MSE & 140.5669 & 125.1484 & 122.2878 \\
\hline & PSNR & 26.6520 & 27.1565 & 27.2570 \\
\hline \multirow{2}{*}{$\begin{array}{l}\text { rbio1. } \\
3\end{array}$} & MSE & 84.1810 & 75.5484 & 75.1166 \\
\hline & PSNR & 28.8787 & 29.3485 & 29.3734 \\
\hline \multirow{2}{*}{$\begin{array}{l}\text { rbio1. } \\
5\end{array}$} & MSE & 188.6351 & 169.4591 & 164.7809 \\
\hline & PSNR & 25.3746 & 25.8402 & 25.9617 \\
\hline \multirow{2}{*}{$\begin{array}{l}\text { rbio2. } \\
2\end{array}$} & MSE & 84.6084 & 75.4751 & 74.9051 \\
\hline & PSNR & 28.8567 & 29.3528 & 29.3857 \\
\hline \multirow{2}{*}{$\begin{array}{l}\text { rbio2. } \\
4\end{array}$} & MSE & 186.1865 & 167.2532 & 162.6933 \\
\hline & PSNR & 25.4313 & 25.8971 & 26.0171 \\
\hline \multirow{2}{*}{$\begin{array}{l}\text { rbio2. } \\
6\end{array}$} & MSE & 101.0028 & 89.0975 & 87.8802 \\
\hline & PSNR & 28.0875 & 28.6321 & 28.6919 \\
\hline
\end{tabular}

\begin{tabular}{|lllll|}
\hline rbio2. & MSE & 233.8773 & 212.5610 & 206.4522 \\
\cline { 2 - 5 } $\begin{array}{l}\mathbf{8} \\
\mathbf{1}\end{array}$ & PSNR & 24.4409 & 24.8560 & 24.9826 \\
\cline { 2 - 5 } & PSNR & 23.7175 & 24.2160 & 24.3667 \\
\hline $\mathbf{3 b i o 3}$. & MSE & 124.0257 & 109.3075 & 107.0878 \\
\cline { 2 - 5 } & PSNR & 27.1957 & 27.7443 & 27.8334 \\
\hline rbio3. & MSE & 259.0130 & 236.4746 & 229.7383 \\
\cline { 2 - 5 } $\mathbf{5}$ & PSNR & 23.9976 & 24.3930 & 24.5185 \\
\hline rbio3. & MSE & 164.2735 & 146.5617 & 142.8153 \\
\cline { 2 - 5 } $\mathbf{7}$ & PSNR & 25.9751 & 26.4706 & 26.5831 \\
\hline rbio3. & MSE & 121.2549 & 107.0014 & 104.9318 \\
\cline { 2 - 5 } $\mathbf{9}$ & PSNR & 27.2938 & 27.8369 & 27.9217 \\
\hline $\begin{array}{l}\text { rbio4. } \\
\mathbf{4}\end{array}$ & MSE & 188.3078 & 169.1083 & 164.4622 \\
\cline { 2 - 5 } & PSNR & 25.3821 & 25.8492 & 25.9701 \\
\hline rbio5. & MSE & 262.3553 & 239.6271 & 232.6387 \\
$\mathbf{5}$ & PSNR & 23.9419 & 24.3354 & 24.4640 \\
\hline rbio6. & MSE & 235.3314 & 213.8630 & 207.6810 \\
\cline { 2 - 5 } & PSNR & 24.4140 & 24.8194 & 24.9568 \\
\hline
\end{tabular}

rbio2.2 gives the best and most appropriate values for both the parameters; hence, rbio2.2 is the best member of this wavelet family for noise removal.

In the same manner experiment was complete with other noise e.g. salt and paper and Speckle Noise.

\section{CONCLUSION}

In the present work we discuss different noises like Gaussian, salt and pepper, and speckle noise along with their PDF. We also explained various spatial filtering techniques and various image De-noising performance parameters. It is concluded that filtering is important in order to reconstruct a good quality image from a noisy image and various parameters help to identify which filter is best for removing a particular noise. The ideal values for parameters are 0 for MSE, 100000 for PSNR (as high as possible).

Next, frequency domain filtering is applied on noisy images and then wavelets are applied. The result for MSE and PSNR are calculated and tabulated. The results make it clear that the output image obtained after wiener filter and wavelets gives the most suitable values for both the quality parameters i.e. MSE \& PSNR. The results also reveal that thesome wavelets are independent of noise or work properly and others are not supported in MATLAB. This is also explained with the help of table given below. In Future, noise models, filters and performance parameters can be increased in number in order to obtain a much clear view, concerning decision regarding particular filter selection for a noise type. 
Table 9:Relationships between Noise and Wavelet

\begin{tabular}{|c|c|c|c|}
\hline $\begin{array}{l}\text { Wavelets } \\
\text { correspondin } \\
\text { g noise }\end{array}$ & $\begin{array}{l}\text { Gaussia } \\
\text { n }\end{array}$ & $\begin{array}{l}\text { Salt \& } \\
\text { peppe } \\
\text { r }\end{array}$ & $\begin{array}{l}\text { Speckl } \\
\text { e }\end{array}$ \\
\hline Haar & Y & Y & Y \\
\hline Daubchies & $Y$ & Y & $Y$ \\
\hline Symlet & $\mathrm{Y}$ & Y & Y \\
\hline Dmey & Y & $Y$ & Y \\
\hline Coiflets & Y & Y & Y \\
\hline Bior & $Y$ & $Y$ & $Y$ \\
\hline Rbio & Y & Y & Y \\
\hline Morlet & $\mathrm{N}$ & $\mathrm{N}$ & $\mathrm{N}$ \\
\hline Cgau & $\mathrm{N}$ & $\mathrm{N}$ & $\mathrm{N}$ \\
\hline Shannon & $\mathrm{N}$ & $\mathrm{N}$ & $\mathrm{N}$ \\
\hline Fbsp & $\mathrm{N}$ & $\mathrm{N}$ & $\mathrm{N}$ \\
\hline Cmor & $\mathrm{N}$ & $\mathrm{N}$ & $\mathrm{N}$ \\
\hline Mexh & $\mathrm{N}$ & $\mathrm{N}$ & $\mathrm{N}$ \\
\hline Morl & $\mathrm{N}$ & $\mathrm{N}$ & $\mathrm{N}$ \\
\hline Meyr & $\mathrm{N}$ & $\mathrm{N}$ & $\mathrm{N}$ \\
\hline
\end{tabular}

\section{REFERENCES}

[1] Archana, Sheenam, AmitChhabra, "comprehensive review of Denoising techniques in image restoration," International Journal of Innovative Research in Computer and Communication Engineering (ijircce) Vol.2, Issue6, June2014

[2] NishthaAttlas, Dr. Shefali Gupta, "Wavelet based Techniques for Speckle Noise Reduction in Ultrasound Images," International Journal of Engineering Research and Applications (ijera) vol. 4, Issue 2, February 2014, pp.508-513

[3] Anutam, rajni, "Performance Analysis of Image Denoising with Wavelet Thresholding methods for different levels of decomposition," The International Journal of Multimedia \& itsApplications(IJMA) vol.6, no.3, June 2014

[4] Manjumandot, Shrustiporwal, "Overview on Noise, Types of Noises which corrupts the digital images and the LSH-frequency domain filtering technique to remove noise in medical ultrasound image," International Journal of scientific research volume3, issue:7, July 2014

[5] HazimG.Daway, "Removal of high density salt and pepper noise depending on mode filter," International journal of application or innovation in engineering and management (IJAIEM) volume 3, Issue 6, June 2014.

[6] Vikas Gupta, Rajesh Mahle, Raviprakash S Shriwas, "Image Denoising using Wavelet Transform Method," 978-1-4673-5999-3/13/\$31.00 @2013 IEEE.

[7] Hari Om, MantoshBiswas "An Improved Image Denoising Method Based on WaveletThresholding," Journal of Signal and Information Processing, 2012, 3, 109-116.

[8] P. Hedaoo and S. S. Godbole, "Wavelet Thresholding Approach for Image Denoising, International Journal of
Network Security \& Its Applications, Vol. 3, No. 4, 2011, pp. 16-21.

[9] V. Nigam, S. Luthra and S. Bhatnagar, "A Comparative Study of Thresholding Techniques for Image Denoising," 2010 International Conference on Computer and Communication Technology, Allahabad, 17-19 September 2010, pp. 173-176.

[10] Ajay Boyat, Brijendra Kumar Joshi, "Image Denoising using Wavelet Transform and Median Filtering" 2013 Nirma University International Conference on Engineerin (nuicon77 e), 978-1-4799-0727-4/13/\$31.00 C)2013 ieee.

[11] Hancheng $\mathrm{Yu}$, Li Zhao, and Haixian Wang, "Image Denoising Using TrivariateShrinkag Filter in the Wavelet Domain and Joint Bilateral Filter in the Spatial Domain," ieee transactions on image processing, vol. 18 , no. 10 , october 2009

[12] Sho Miura, Hiroyuki Tsuji, Tomoaki Kimura, "Randomly valued impulse noise removal usinggaussian curvature of image surface," 978-1-4673-63617/13/\$31.00c 2013 IEEE

[13] S. H. Teoh and H. Ibrahim "Median Filtering Frameworks for Reduction Impulse Noise from Grayscale Digital Images: A Literature SurveyInternational," Journal of Future Computer and Communication, vol. 1, no. 4, December 2012.

[14] T. kaur, M. Sandhu and P. Goel, "Performance Comparison of Transform Domain for Speckle Reduction in Ultrasound Image" International Journal of Engineering Research and Application, vol. 2, issue 1, pp.184-188.

[15] Z. Wang, A.C. Bovik, H.R. Sheikh, and E.P. Simoncelli, "Image quality assessment: from error visibility to structural similarity", IEEE Trans. Image Process., vol. 13, no. 4, pp. 600- 612, Apr. 2004.

[16] N. Damera-Venkata, T.D. Kite, W.S. Geisler, B.L. Evans, and A.C. Bovik, "Image quality assessment based on a degradation model", IEEE Trans. Image Process., vol. 9, no. 4, pp. 636- 650, Apr. 2000.

[17] D.M. Chandler and S.S. Hemami, "VSNR: a waveletbased visual signal-to-noise ratio for natural images", IEEE Trans. Image Process., vol. 16, no. 9, pp. 22842298, Sep. 2007.

[18] H.R. Sheikh and A.C. Bovik, "Image information and visual quality”, IEEE Trans. Image Process, vol. 15, no. 2, pp. 430-444, Feb. 2006.

[19] J. N. Ellinas, T. Mandadelis, A. Tzortzis, L. Aslanoglou, "Image de-noising using wavelets," T.E.I. of Piraeus, Department of Electronic Computer Systems.

[20] PriyaKapoor, Samandeep Singh, “An Improved Modified Decision Based Filter to Remove High Density Impulse Noise," International Journal of Advanced Research in Computer Science and Software Engineering, Volume 4, Issue 7, July 2014, ISSN: 2277 128X.

[21] AyushiJaiswal, Ravi Mohan, Meenal Jain, "A Novel Noise Reduction Method for Image and Video Denoising," International Journal of Advanced Research in Computer Science and Software Engineering, Volume 4, Issue 7, July 2014, ISSN: 2277 128X. 
[22] S.Maheshwari, "A Study on Image Restoration Techniques," International Journal of Advanced Research in Computer Science and Software Engineering, Volume 4, Issue 5, May 2014, ISSN: 2277 $128 \mathrm{X}$.

[23] Kumar, T. and K. Verma, A theory based on conversion of RGB image to gray image. Int. J. Computer. Appli., 7: 5-12. DOI: 10.5120/1140-1493, 2010.

[24] Aditi Singh, KrishankantNayak, "Analysis of Image Noise Removal Methodologies for High Density Impulse Noise," IJCSMC, Vol. 3, Issue. 6, June 2014, pg.659 - 665, ISSN 2320-088X.

[25] AlkaVishwa, Shilpa Sharma, "Speckle Noise Reduction in Ultrasound Images by Wavelet Thresholding," International Journal of Advanced Research in Computer Science and Software Engineering, Volume 2, Issue 2, February 2012, ISSN: 2277 128X.

[26] Manjumandot, Shrustiporwal, "Overview on Noise, Types of Noises which corrupts the digital images and the LSH-frequency domain filtering technique to remove noise in medical ultrasound image," International Journal of scientific research volume3, issue:7, July 2014

[27] HazimG.Daway, "Removal of high density salt and pepper noise depending on mode filter," International journal of application or innovation in engineering and management (IJAIEM) volume 3, Issue 6, June 2014.

[28] Hemajagadish, J.Prakash, "A new approach for Denoising remotely sensed images using DWT based Homomorphic filtering techniques," International journal of emerging trends and Technology in computer science (IJETTCS) vol. 3, issue 3, may-june 2014.

[29] Ravi Kumar, Munish rattan, "Analysis of various quality metrics for medical image processing," International journal of advanced research in computer science and software Engineering(ijarcsse) volume 2, Issue 11, November 2012.

[30] SachinRuikar, Dr. D DDoye, "Image Denoising Using Wavelet Transform," 2010 International Conference on Mechanical and Electrical Technology (ICMET 2010), Singapore, September 2010, pp. 509-515. 